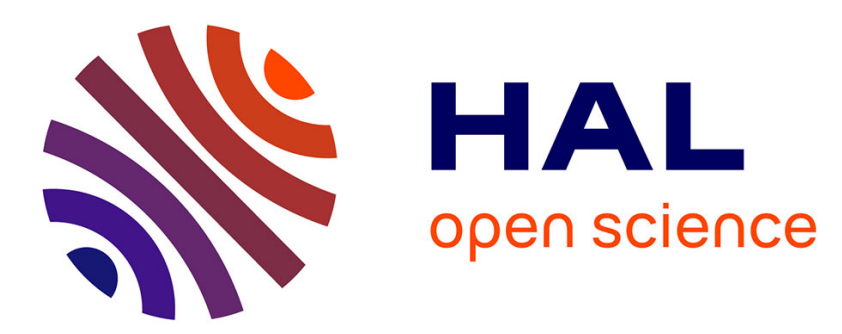

\title{
From pixel to vine parcel: A complete methodology for vineyard delineation and characterization using remote-sensing data
}

Carole Delenne, Sylvie Durrieu, Gilles Rabatel, Michel Deshayes

\section{- To cite this version:}

Carole Delenne, Sylvie Durrieu, Gilles Rabatel, Michel Deshayes. From pixel to vine parcel: A complete methodology for vineyard delineation and characterization using remote-sensing data. Computers and Electronics in Agriculture, 2010, 70 (1), pp.78-83. 10.1016/j.compag.2009.09.012 . hal01196894

\section{HAL Id: hal-01196894 \\ https://hal.science/hal-01196894}

Submitted on 10 Sep 2015

HAL is a multi-disciplinary open access archive for the deposit and dissemination of scientific research documents, whether they are published or not. The documents may come from teaching and research institutions in France or abroad, or from public or private research centers.
L'archive ouverte pluridisciplinaire HAL, est destinée au dépôt et à la diffusion de documents scientifiques de niveau recherche, publiés ou non, émanant des établissements d'enseignement et de recherche français ou étrangers, des laboratoires publics ou privés. 


\title{
From pixel to vine parcel: a complete methodology for vineyard delineation and characterization using remote-sensing data
}

\author{
Carole Delenne ${ }^{\mathrm{b}}$ Sylvie Durrieu ${ }^{\mathrm{b}}$ Gilles Rabatel ${ }^{\mathrm{a}}$ \\ Michel Deshayes ${ }^{b}$ \\ ${ }^{a}$ UMR ITAP - Cemagref - Montpellier, France \\ ${ }^{\mathrm{b}}$ UMR TETIS - Remote Sensing Center - Montpellier, France
}

\begin{abstract}
The increasing availability of Very High Spatial Resolution images enables accurate digital maps production as an aid for management in the agricultural domain. In this study we develop a comprehensive and automatic tool for vineyard detection, delineation and characterization using aerial images and without any parcel plan availability. In France, vineyard training methods in rows or grids generate periodic patterns which make frequency analysis a suitable approach. The proposed method computes a Fast Fourier Transform on an aerial image, providing the delineation of vineyards and the accurate evaluation of row orientation and interrow width. These characteristics are then used to extract individual vine rows, with the aim of detecting missing vine plants and characterizing cultural practices. Using the red channel of an aerial image, $90 \%$ of the parcels have been detected $(56.2 \%$ with correct boundaries); $92 \%$ have been well classified according to their rate of missing vine plants and $81 \%$ according to their cultural practice (weed control method). The automatic process developed can be easily integrated into the final user's Geographical Information System and produces useful information for vineyard management.
\end{abstract}

Key words: Remote-sensing, precision viticulture, cultural practices, missing vine plants, segmentation.

\section{Introduction}

Since they provide precise and frequent large scale information, remote-sensing data can be used as an aid to decision-making. In winegrowing regions, accurate digital vineyards maps could be very useful to help the monitoring of quality compliance, especially for Controlled Origin Denomination areas,

Preprint submitted to Elsevier Science 3 October 2008 
where strict criteria are imposed, such as a rate of missing vine plants below $25 \%$. The management of pollution, erosion and flood risks are other fields that can take advantage of such maps as these risks depend on soil surface conditions, which are directly linked to the kind of culture and cropping practice (see for example Lennartz et al. [1997] or Takken et al. [2001]). Distributed hydrological models developed for cultivated catchments take into account the spatial heterogeneity of landscape through some characteristics of crop pattern and cultural practices. However, these characteristics are generally unknown and are thus simulated using geostatistical methods and some localized and costly field surveys. Consequently, information (even partial) on soil surface condition between rows could be usefully introduced in such models. Users' demands usually concern (1) vineyards location and delineation and (2) identification of some characteristics that can be connected to cropping practices or crop quality, such as interrow width, row orientation, presence of grass between rows or missing vine plants (Montesinos Aranda and Quintanilla [2006]). Many vineyard related studies in remote sensing (such as Lamb et al. [2004] or Zarco-Tejada et al. [2005]) use the infrared channel of low spatial resolution images to characterize vine vigour. On Very High Spatial Resolution (VHSR) images, the plantation and training patterns (often in rows or grids) become distinguishable, providing great discrimination and characterization potentialities. However, realizing this potential with automatic processes requires the development of new image processing approaches, allowing the analysis of textured image. Two kinds of approaches have been used to that aim for vineyard characterization: texture and frequency analysis. The former has recently been used by Da Costa et al. [2007] to extract vineyards boundaries from $0.15 \mathrm{~cm}$ resolution images. However, a main drawback of the approach relies on the necessity to select a window inside each vine block before processing and the efficiency of the method in not quantified since results were qualitatively validated through a non-exhaustive visual control. Moreover, a comparative study of methods for vineyards detection (Delenne et al. [2008a]) has shown the inferiority of such kind of textural approach in comparison with a frequency analysis. This later, which takes advantage of the crop patterns periodicity, has been successfully used by Wassenaar et al. [2002] who applied a Fourier Transform to characterize already delineated vine blocks on $25 \mathrm{~cm}$ resolution images. This approach also enables the accurate estimation of interrow width and row orientation, which can be used to easily extract and characterize each vine row, contrary to the complex and time-consuming classical methods of deformable models, such as used in Bobillet et al. [2003]. The 'vinecrawler' algorithm presented in Hall et al. [2003] and successfully applied on Australian vineyards, would be difficultly usable in our case where vine rows and interrows rarely contain more than two or three pixels (see section 'Study area and data'). This paper addresses the issue of vineyard detection, delineation and characterization from VHSR aerial images using a frequency analysis approach. The originality of the developed method stands in the fact that it is entirely automatic and produces a geographic data base in a 'shape- 
file' format, which can be integrated into any GIS used by vineyard managers. The first part of this paper describes the proposed approach and the study area. Considering that the main objective of this paper is to present the whole workflow process, assessment of method efficiency is only presented for tests done on the red channel of an aerial image with a $50 \mathrm{~cm}$ spatial resolution. This choice (discussed in the section 'Study area and data') was guided by the increasing availability of such images in Europe and by results obtained in previous studies (Wassenaar et al. [2002], Delenne [2006]).

\section{Material and method}

In the following, the term 'parcel' will refer to an individual vineyard block with homogeneous characteristics (row orientation, interrow width, agricultural practice...). The process workflow can be divided in three main steps: (1) vineyard detection, (2) initial parcel delineation, and (3) vine row extraction, allowing boundaries refinement. At each step, some characteristics are derived, either to be directly added in the user's geographical database or to be used in a further processing step.

\subsection{Study area and data}

The study area is the Roujan catchment (southern France), which has been an experimental site for hydrological studies since the beginning of the 90's. In this Mediterranean coastal plain, the diversity of agricultural practices leads to a great heterogeneity among the vineyards to be detected on remote sensing data. However, according to training mode, two main patterns can be observed: grid or line. About a quarter of the vineyards considered in this study are trained in 'goblet', involving no wire or other support system and leading to a grid pattern, often square, with approximately $1.5 \times 1.5 \mathrm{~m}$ spacing. The line pattern concerns most of the recent vineyards, which are trained using horizontal wires to which the fruiting shoots are tied. Spacing between vine plants in the same row is smaller than spacing between rows (often $1 \times 2.5 \mathrm{~m}$ spacing in the study area). More adapted to mechanization, this nowadays widespread training mode is named trellis or wire-training. Weed control practices in the study area are based on three main methods: chemical weeding, mechanical weeding and grass cover. Cultural practices are characterized by either applying the same weed control practice on each interrow or alternating various weed control practices. The main combination modalities are: 1/1 (no alternation of practices), 1/2 (e.g. interrows alternatively grass covered and chemically weeded), $1 / 3$ or $1 / 4$. Data acquisition was made during the first week of July 2005, when foliar development was such that both vine and soil 
were visible on aerial photographs, providing enhanced pattern visibility. Digital cameras were used aboard an Ultra Light Aircraft to acquire RGB (three channels in the visible part of the electromagnetic spectrum: red, green and blue) and infrared images, with a spatial resolution of $50 \mathrm{~cm}$. These characteristics have been chosen because they correspond to largely available data in Europe. Preliminary tests done on the Blue, Green, Red, Near Infrared channels and on the NDVI and Green-NDVI indices (Delenne [2006]) have shown that best results are obtained with the Red channel. This is mainly due to the fact that the contrast between vine rows (vegetation) and interrows is generally better in the red channel and especially when the interrows are covered by grass. The influence of resolution has also been studied and it was demonstrated that resolutions ranging from $30 \mathrm{~cm}$ to $50 \mathrm{~cm}$ were optimal according to the interrow widths encountered (Delenne [2006]). Thus, only results of the processing of the $50 \mathrm{~cm}$ resolution red channel will be presented in this paper. For result validation, ground-truth information was collected at the same time as image acquisition. The 121 vine parcels of the study area have been digitized in a GIS database which also contains information concerning land use and, for vineyards, characteristics of training mode (row or grid pattern), interrow width, orientation and soil surface condition between rows and under vine plants (covered by grass, chemically or mechanically weeded). Reference row orientations and interrow widths were obtained by precise onscreen measurements: row orientation was measured with a 1 precision and interrow width was calculated by dividing the width of the whole parcel by the number of interrows. In the following, this data base will be called the reference database.

\subsection{Vine parcel detection and boundaries extraction}

This part is based on previously published works and is thus briefly recalled here.

Fourier theory (named after Joseph Fourier) states that almost any signal, including images, can be expressed as a sum of sinusoidal waves oscillating at different frequencies. Thanks to the Fast Fourier Transform (FFT) algorithm (Cooley and Tukey [1965]), the discrete Fourier transform of an image $I$ can be quickly computed. Its amplitude, or Fourier spectrum, can be represented in the frequency domain as an image $\hat{I}$, symmetric with respect to its center. Each position $(u, v)$ in the Fourier spectrum corresponds to a particular spatial frequency increasing the further it is from image center. A periodic pattern in the spatial image $I$ will induce a high value of the associated pixel in image $\hat{I}$. The method is thus based on the fact that vineyards are, most of the time, organized in rows or grid and induce very located peaks. The location of these peaks also enables the precise estimation of row orientation and interrow 
width, which will be useful in the next steps of vineyard characterization (see section Results). Two methods, based on this principle, have been developed for vineyard boundaries extraction: the first one, at an inner-parcel scale, classifies each pixel in vine/non-vine using the FFT on its near-neighborhood (about $30 \mathrm{~m}^{2}$ ) before segmenting the resulting image in vine parcels (Delenne [2006] and Delenne et al. [2006]); the second one, at a more global scale, treats image subsets (about $500 \mathrm{~m}^{2}$ ) containing several vine parcels at the same time and performs the segmentation directly in a recursive process (Rabatel et al. [2008] and Delenne et al. [2008b]). The first method is much simpler to implement and provides equivalent results in terms of detected parcels but with less accuracy in boundaries location.

\subsection{Vine row extraction: a way to improve delineation and characterization}

The characteristics of row orientation and interrow width are used in this step to extract each vine row in the segmented parcel. The two main objectives of this extraction are the improvement of boundaries location by a precise adjustment of each row and the foliar density characterization at row level (with the out-coming detection of missing vine plants). Row extraction includes 3 steps: 1) identification of the rows inside the previously delineated parcels, 2) adjustment of the vine row network and 3) use of the final network to improve and complete the geographical database.

\subsubsection{Initial row network extraction}

The first step of vine row extraction consists in setting a row 'network' inside the previously segmented parcels. Assuming that rows are parallel, the straightforward proposed approach firstly consists in filling the parcel with a high number of oriented segments (e.g. spaced by half a pixel). Then, segment corresponding to vine rows are selected using two constraints based on digital numbers (DN) values and interrow width. In general, vegetation reflectance is lower than soil one in red wavelengths. For vineyards, the pattern contrast is sharpened in the red spectral band, thanks to the vine plants shadow located under the row when the sun elevation is high. Based on the hypothesis that vine row DN are lower than soil ones, local minima are first identified to select vine rows. Some of these minima, which are not located on vine rows, are eliminated using a second selection constraint based on a minimum interrow width (Figure 1). 

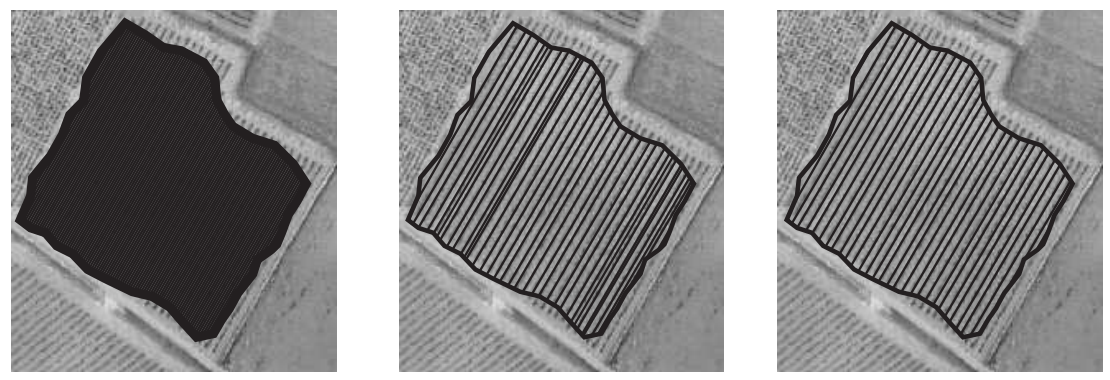

Fig. 1. Vine row detection. Left: row network initial setting; middle: elimination of false rows using the constraint of digital number local minima; right: further elimination using the constraint of minimum interrow width.

\subsubsection{Network adjustment on the parcel neighbourhood}

The row network is precisely adjusted using four actions: two row length adjustments, shortening and lengthening, and two adjustments of row number, elimination and addition. In the following, the two classes 'row' and 'interrow' are considered (the interrows being defined by translating the rows of half an interrow width, perpendicularly to row orientation). The general algorithm of this adjustment process is presented in Figure 2. For row length adjustment (shortening and lengthening), one meter length segments - corresponding to the mean interplant distance along a row encountered in the study area - are considered at row ends. The mean DN of a segment is compared to the DN distribution of the entire row and to the DN distribution of the both adjacent interrows using the Mahalanobis distance (introduced by P. C. Mahalanobis in 1936) defined by equation 1 :

$$
d_{M}=\sqrt{\frac{(v-\mu)}{\sigma^{2}}}
$$

with $v$ the value to test, $\mu$ and $\sigma^{2}$ the distribution mean and variance respectively. This distance (unlike the Euclidian one) is invariant to any change of scale and gives an estimation of the possibility for an element to belong to a class. Thus, if the segment mean DN is closer to the class 'row' than the class 'adjacent interrows', the segment is considered to belong to the row. Lengthening is first tested by adding a segment to the row until it is no more classified as 'row'. If the initial lengthening fails, segment elimination is tried. Additional tests check the presence of interrow segments at both sides of the row to avoid some false detection due to objects having the same range of DN values as vine rows (such as trees). Once initial rows are adjusted, the next step consists in row elimination or addition based on the analysis of the whole row mean DN value. Concerning the elimination process, each row mean DN value is compared to the global distribution of the mean DN values of all the rows and interrows of the parcel. The removal occurs when the row mean DN value is closer to the interrows class than the row one. The same kind of test is carried out to try to add some rows at the edges of the parcel. 


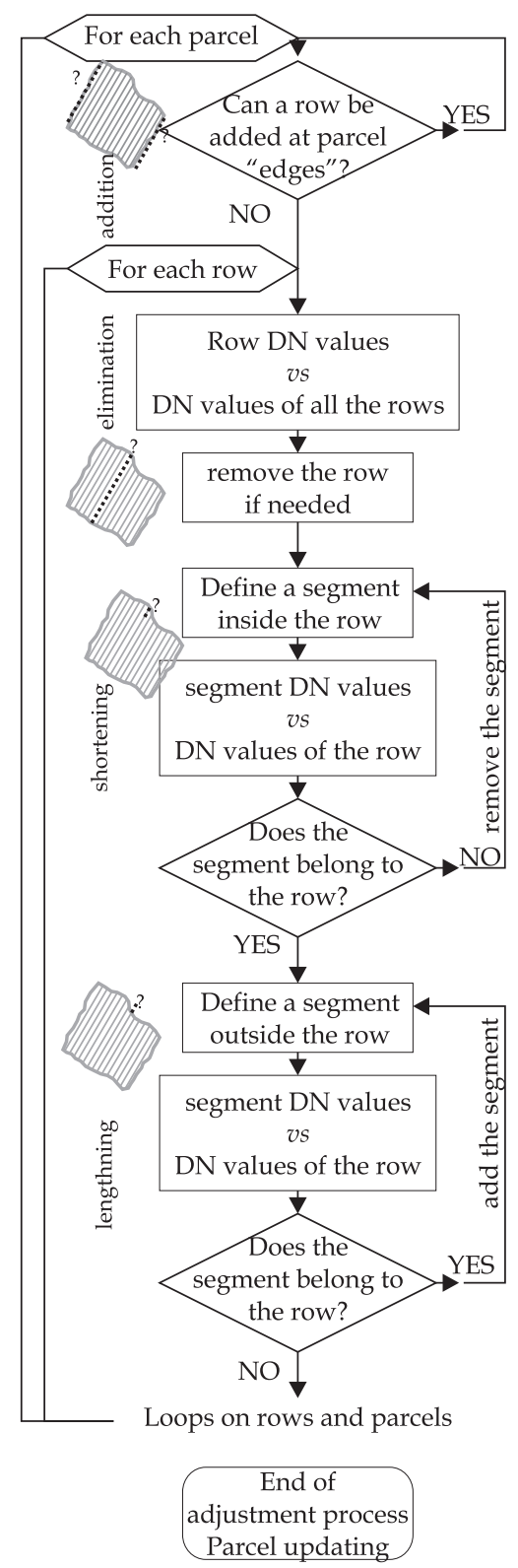

Fig. 2. chart of the adjustment process.

\subsubsection{Parcel update in the geographical database}

When all the rows have been adjusted, the parcel boundaries need to be corrected accordingly. At this stage, if some rows belonging to different parcels but having the same orientation and interrow width overlap each other, the corresponding parcels are grouped. This enables the correction of some oversegmentation cases. On the contrary, when more than three consecutive rows have been eliminated, the parcel is split up into two new parcels. This enables the correction of some under-segmentation cases. Figure 3 shows some improvements of parcel delineation after row detection and adjustment (see section Results for more details). 

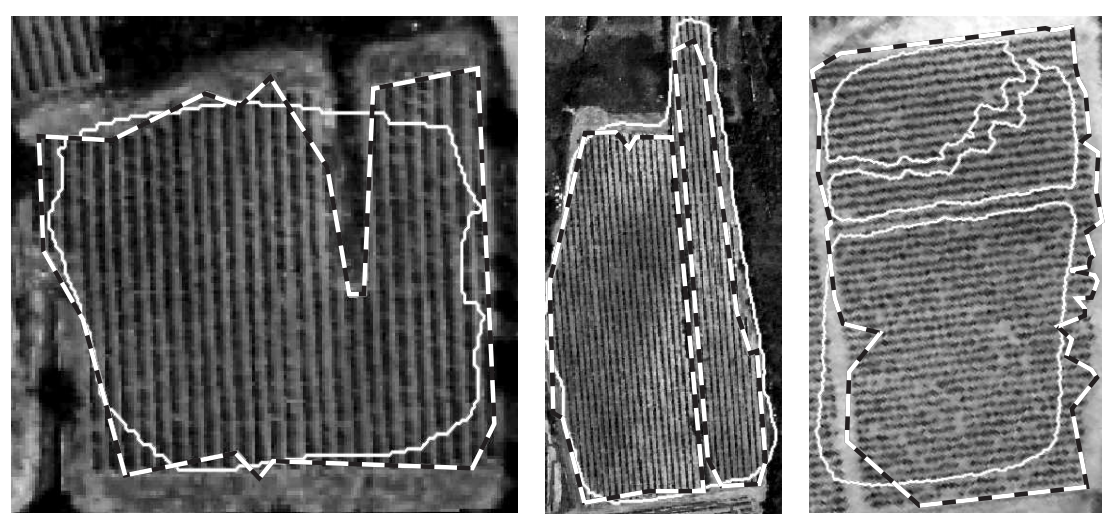

Fig. 3. Parcel boundaries improvement thanks to row adjustment (left), elimination (middle) and addition (right). Continued lines: initial boundaries; discontinued lines: adjusted ones.

\subsubsection{Detection of missing vine plants}

The missing plant detection is processed in a similar way as row length adjustment. Each row is divided in $1 \mathrm{~m}$ length segments and the mean DN value of each segment is compared to the DN distribution of the row and the both adjacent interrows. When the distance to the interrow class is smaller than the one to the row class, the segment is considered to correspond to a missing vine plant. The non-detection of missing vine plants can be due to the presence of grass under the row (so that the interrow radiometry is close to the row one) or to the fact that the gap has been filled by the two neighbour plants. On the contrary, some plants can be wrongly considered as missing for several reasons: the missing vine plant has been recently replaced and is not yet visible on the image; the plant is not missing but is not very sturdy; the interrow is covered by grass so that the difference between row and interrow is poor... (see section Results for more details).

\subsubsection{Soil surface characterization: alternation of weed control methods}

When alternation of weed control methods is observed, another periodical pattern appears on the image with a frequency twice or three or four times smaller as the one characterizing the row (according to the combination modality). To automatically assess this secondary pattern, the one dimensional Fourier transform is computed for each parcel on the signal made by the interrows DN means. Then, knowing the interrow frequency $f$, the process seeks for a second local maximum and estimates its frequency $f_{2}$. There will be alternation if the frequency $f_{2}$ is approximately equal to $f / 2, f / 3$ or $f / 4$. 


\begin{tabular}{|c|c|}
\hline Case & Meaning \\
\hline 1. Good segmentation & $\begin{array}{l}\text { The common covering surface is higher than } 70 \% \text { of both } \\
\text { manually and automatically segmented parcels. }\end{array}$ \\
\hline 2. Over-segmentation & $\begin{array}{l}\text { Several parcels are automatically segmented within one } \\
\text { real parcel. }\end{array}$ \\
\hline 3. Under-segmentation & $\begin{array}{l}\text { One automatically segmented parcel includes several real } \\
\text { parcels. }\end{array}$ \\
\hline 4. Partial segmentation & Only one part of the real parcel is detected. \\
\hline 5. Larger segmentation & $\begin{array}{l}\text { The automatically segmented parcel spills over one or more } \\
\text { parcels. }\end{array}$ \\
\hline 6. Missing segmentation & Vine parcels not automatically segmented. \\
\hline 7. Extra segmentation & Non-vine parcels automatically segmented as vine. \\
\hline 8. Other cases & $\begin{array}{l}\text { All other cases such as both over and under segmentation } \\
\text { or both under and partial segmentation. }\end{array}$ \\
\hline
\end{tabular}

Table 1

Segmentation result classification: 8 different cases can be considered.

\section{Results}

\subsection{Segmentation results before and after row adjustment}

For the validation process, the results of vine parcel segmentation are classified using the 8 different cases defined in Table 1, according to their compliance with the reference boundaries (see Rabatel et al. [2008] for more details).

Segmentation results obtained on the red channel of the image are presented in Table 2 before and after row adjustment. These results have been obtained with the first cited approach (Delenne et al. [2006]). As presented in Rabatel et al. [2008], On the former results, only 12 parcels (10\%) are not detected, all of them - except one - being smaller than 0.5 ha and thus leading to weak amplitude peak in the Fourier spectrum. Even the very young parcels of the study area (less than three years old) have been detected, thanks to the enhancement of the image contrast. Nearly half the parcels have been correctly segmented (case 1), and many have been under (14.8\%) or partially segmented $(10.7 \%)$. As shown in the second column of Table 2, the rows detection and adjustment process enhances these first results in many ways, leading to a raise of correctly segmented parcel rate from $48 \%$ to $56.2 \%$. No further improvement step can be envisaged concerning the case of missing segmentation, which contains one more parcel after a too important shortening of its rows. However, this case concerns less than $5 \%$ of the study area and these kinds 


\begin{tabular}{lcc}
\hline Case & Before row adjustment & After row adjustment \\
1. Good & $58(48 \%)$ & $68(56.2 \%)$ \\
2. Over & $3(2.5 \%)$ & $1(0.8 \%)$ \\
3. Under & $18(14.8 \%)$ & $19(15.7 \%)$ \\
4. Partial & $13(10.7 \%)$ & $9(7.5 \%)$ \\
5. Larger & $8(6.6 \%)$ & $3(2.5 \%)$ \\
6. Missing & $12(10 \%)$ & $13(10.7 \%)$ \\
7. Extra & $7(-)$ & $3(-)$ \\
8. Other & $9(7.4 \%)$ & $8(6.6 \%)$ \\
\hline
\end{tabular}

Table 2

Segmentation results (in parcel and percentage) obtained on the red channel of a $50 \mathrm{~cm}$ resolution image, before and after row adjustment, for the 121 vine parcel of the Roujan study site.

of small parcels tends to be no more exploited due to the general increase of mechanization.

\subsubsection{Characterization results}

3.1.1.1 Interrow width and row orientation Between on-screen measurements and method-derived estimates, average absolute differences of less than $1^{\circ}$ and $3.3 \mathrm{~cm}$ have been found respectively for row orientation and interrow width. As shown in Figure 4, the coefficients of determination $R^{2}$ obtained when comparing computed parameters to reference data are almost equal to 1 for both characteristics. Moreover, it could be visually assessed in the step of row extraction that the reference rows orientations (obtained by photo-interpretation) are less accurate than the automatically computed ones.

3.1.1.2 Missing vine plants detection Figure 5 shows some examples of results obtained with the proposed method. An exhaustive validation could not be done because of the lack of ground data. The following classification (done by photo-interpretation) is thus used: (1) less than $15 \%$ of missing vine plants, (2) between $15 \%$ and 30\%, (3) more than 30\%. The confusion matrix of this classification is given in Table 3 for all the vine parcels of the study area except seven very young vineyards for which vine plants are not visible by photo-interpretation. These results are very satisfactory since $92 \%$ of the parcels have been well classified. This kind of information will be useful for vineyard managers, for example to target the parcels which will need a more specific attention. 

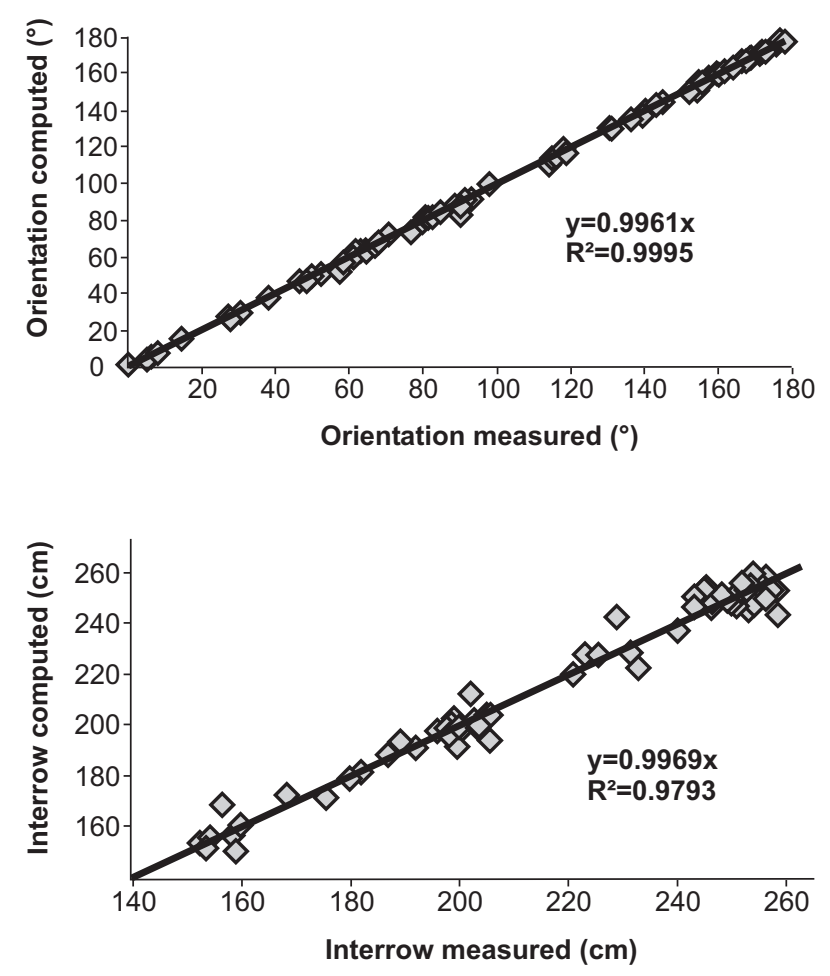

Fig. 4. Interrow width and row orientation: on-screen measurements vs automatic estimation.
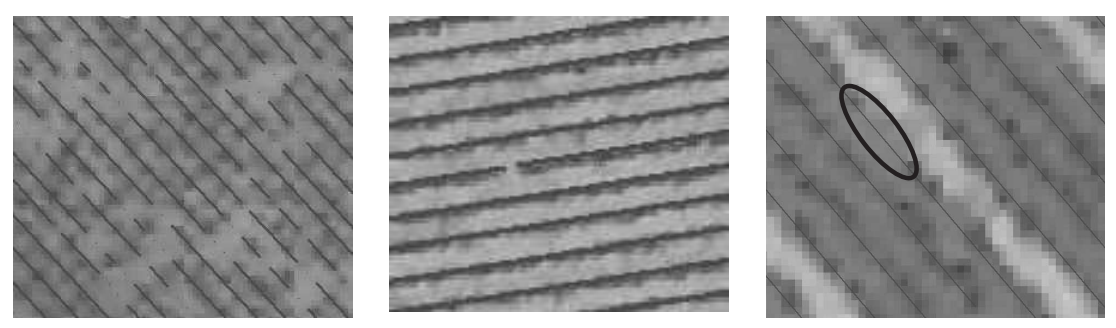

Fig. 5. Examples of missing vine plants detection. Image subsets in parcels having more than $25 \%$ (left) and less than 15\% (middle) of missing plants; detection error due to the presence of grass under the row (right).

\subsubsection{Soil surface characterization: alternation of weed control} methods Confusion matrix for 'alternated parcels' detection is given in Table $4.81 \%$ of the 121 parcels have been well classified. Nearly all the classification errors concern alternated parcels for which the periodic pattern is poorly contrasted in the image (Figure 6a). As a consequence, results obtained concerning parcels with some interrows covered by grass are much satisfactory, with only 4 wrong classifications over 18 . The two non alternated parcels which have been wrongly classified contain some interconnecting farm roads, which induce a secondary and confusing pattern. 


\begin{tabular}{cccc}
\hline & $<15 \%$ & $15 \%<-<30 \%$ & $>30 \%$ \\
$<15 \%$ & 82 & 4 & 0 \\
$15 \%<-<30 \%$ & 1 & 14 & 1 \\
$>30 \%$ & 2 & 1 & 9 \\
\hline
\end{tabular}

Amount of correct classifications: 105/114 (92\%)

Table 3

Confusion matrix concerning vineyard classification in three classes according to their rate of missing vine plants (automatic process in line, photo-interpretation in column).

Table 4

\begin{tabular}{|c|c|c|c|c|}
\hline & $1 / 1$ & $1 / 2$ & $2 / 3$ & $3 / 4$ \\
\hline $1 / 1$ & 85 & 16 & 2 & 0 \\
\hline $1 / 2$ & 1 & 13 & 0 & 0 \\
\hline $2 / 3$ & 0 & 0 & 0 & 0 \\
\hline $3 / 4$ & 1 & 0 & 0 & 3 \\
\hline
\end{tabular}

Confusion matrix concerning vineyard classification according to their cultural practice (alternation of weed control methods). Automatic process in line, photointerpretation in column.
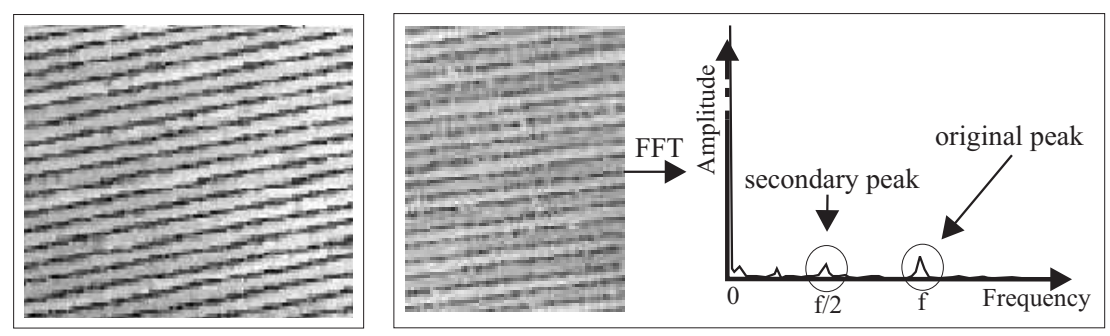

Fig. 6. Left: example of an undetected alternation 1/3 (invisible at naked eye); right: example of an alternation $1 / 2$ and its Fourier spectrum.

\section{Discussion and conclusions}

In this study, a comprehensive process for vineyard detection, delineation and intra-parcel characterization has been proposed. The main advantages of this method are: its easy implementation, processing speed and the limited amount of parameters. It has been implemented in a completely automatic way and exports results into GIS format (.shp) with an associated database containing characteristics such as area, perimeter, interrow width, row orientation, missing vine plants rate and cultural practices. This process, easily integrated in the GIS used by vineyards managers, will enable a considerable reduction of 
the cost previously needed to obtain all these characteristics using on-ground surveys or photo-interpretation. Indeed, the survey done for the validation of this study took two days when it only consisted in checking several characteristics of the parcel without carrying out the differential GPS survey of boundaries. Meanwhile, only about one hour is needed for the automatic process on a personal computer, which may be the same for a manual digitization but do not need such user intervention. Moreover, it has been shown that the automatic estimation of vine row orientation and interrow width are more accurate than those obtained by photo interpretation or ground measurements. As the method description is relatively long, we have chosen to present only the best results, obtained with the red channel of the image. These make us confident regarding the interest of the method as only $10 \%$ of the vine parcels have not been detected in the first step of segmentation, mainly concerning small parcels which tend to be no longer exploited due to their inadequacy with the general mechanization used in viticulture. Although not validated exhaustively, the missing vine plant detection seems to be correctly assessed as $92 \%$ of the parcels have been correctly classified according to three classes of missing plants rate. The results of cultural practices characterization are slightly poorer, except concerning practices involving grass cover. As said in introduction, this information, even partial, will be useful to introduce in distributed hydrological models. As a perspective, a complete evaluation of the method according to different types of input data (resolution, spectral bands, Lidar data... ) will be done and presented in a further paper.

\section{Acknowledgment}

The present study has been partly carried out within the European research project Bacchus (EVG2-2001-00023) with a co-funding from the European Commission and within the MOBHYDIC project of the French national program of research in hydrology. Aerial images were acquired by the Avion Jaune company.

\section{References}

W. Bobillet, J.-P. Da Costa, C. Germain, O. Lavialle, and G. Grenier. Row detection in high resolution remote sensing images of vine fields. In J. Stafford and A. Werner, editors, European Conference on Precision Agriculture, pages 81-87, Berlin, 2003. Wageningen academic publishers.

J. W. Cooley and J. W. Tukey. An algorithm for the machine calculation of complex Fourier series. Mathematics of Computation, 19(90):297-301, 1965. 
P. Da Costa, F. Michelet, C. Germain, O. Lavialle, and G. Grenier. Delineation of vine parcels by segmentation of high resolution remote sensed images. Precision Agriculture, 8(1):95-110, 2007.

C. Delenne. Extraction et caractrisation de vignes partir de donnes de tldtection trs haute rsolution spatiale. PhD thesis, ENGREF, 2006.

C. Delenne, G. Rabatel, V. Agurto, and M. Deshayes. Vine plot detection in aerial images using fourier analysis. In S. Lang, T. Blaschke, and E. Schpfer, editors, 1st International Conference on Object-based Image Analysis (OBIA 2006), 2006.

C. Delenne, S. Durrieu, G. Rabatel, M. Deshayes, J.-S. Bailly, C. Lelong, and P. Couteron. Textural approaches for vineyard detection and characterization using very high spatial resolution remote-sensing data. International Journal of Remote Sensing, 29(4):1153-1167, 2008a.

C. Delenne, G. Rabatel, and M. Deshayes. An automatized frequency analysis for vine plot detection and delineation in remote sensing. IEEE Geosciences and Remote Sensing Letters, 5(3):341-345, 2008b.

A. Hall, J. Louis, and D. Lamb. Characterising and mapping vineyard canopy using high-spatial-resolution aerial multispectral images. Computers and Geosciences, 29:813-822, 2003.

D. W. Lamb, M. M. Weedon, and R. G. V. Bramley. Using remote sensing to predict grape phenolics and colour at harvest in a Cabernet Sauvigon vineyard: Timing observation against vine phenology and optimising resolution. Australian Journal of Grape and Wine Research, 10(1):46-54, 2004.

B. Lennartz, X. Louchart, M. Voltz, and Andrieux P. Diuron and simazine losses to runoff water in mediterranean vineyards as related to agricultural practices. Journal of Environmental Quality, 26:14931502, 1997.

S. Montesinos Aranda and A. Quintanilla. "BACCHUS": methodological approach for vineyard inventory and management. European Commission DG Research, 2006.

G. Rabatel, C. Delenne, and M Deshayes. A non-supervised approach using gabor filters for vine-plot detection in aerial images. Computers and electronics in agriculture, 62:159-168, 2008.

I. Takken, G. Govers, V. Jetten, J. Nachtergaele, A. Steegen, and J. Poesen. Effects of tillage on runoff and erosion patterns. Soil and Tillage Research, 61:55-60, 2001.

T. Wassenaar, J.-M. Robbez-Masson, P. Andrieux, and F. Baret. Vineyard identification and description of spatial crop structure by per-field frequency analysis. International Journal of Remote Sensing, 23(17):33113325, 2002.

P. J. Zarco-Tejada, A. Berjón, R. López-Lozano, J. R. Miller, P. Martín, V. Cachorro, M. R. González, and A. de Frutos. Assessing vineyard condition with hyperspectral indices: Leaf and canopy reflectance simulation in a row-structured discontinuous canopy. Remote Sensing of Environment, 99:271-287, 2005. 